\title{
STUDY AND DESIGN OF INLET MANIFOLD FOR SWIRLING EFFECT
}

\author{
Siddharth Lokhande \\ Department of Mechanical Engineering \\ Ajeenkya D.Y. Patil, Pune, Maharashtra, India \\ Santosh Late \\ Department of Mechanical Engineering \\ Ajeenkya D.Y. Patil, Pune, Maharashtra, India
}

\author{
Vaibhav Mohol \\ Department of Mechanical Engineering \\ Ajeenkya D.Y. Patil, Pune, Maharashtra, India \\ Parag Nagpure \\ Department of Mechanical Engineering \\ Ajeenkya D.Y. Patil, Pune, Maharashtra, India
}

\begin{abstract}
The "swirl" term is preferable to "turbulence", which implies movement without overall pattern of the mixture or fluid. It is a dimensionless parameter to quantity the rotational motion. As our topic name Study and Design of Inlet Manifold for Swirling Effect we are going to swirl the air in pipe which is having specific diameter. Nowadays many geometric shapes and geometric pattern are available for swirling effect but according to application the pattern changes. In our project we are going design a swirling geometry which will be efficient to create a swirl effect. We are going to compare the results of motion of air with swirl and without swirl from our experimental setup. Coming to our methodology we are going to build a setup which consist of water pump, swirling component or geometry. Firstly, we are going to study effect of three designed geometry and will checked for optimum swirling effect by using CFD software. After selecting optimum geometry, we are going to install selected geometry in pipe through which water is going to be passed. With the help of water pump and flow control valve we can set up the pressure and flow of water at inlet. After passing the water through the swirling geometry we are going to measure the outlet parameter i.e. Discharge and velocity. Then we are going to determine whether the Swirling effect has been practically achieved or not, by comparing the results obtained from CFD analysis and experimental setup.
\end{abstract}

Keywords-Swirling Effect, Swirl geometry, Cfd, Inlet Manifold

\section{INTRODUCTION}

Due to heterogeneous combustion the thermal efficiency of C.I. Engine is less in spite of using a large excess air. Therefore, thought of conducting the experiment to overcome the problem of low thermal efficiency \&also to reduce levels of pollution. The thermal efficiency of the conventional C.I. Engine is low around $20 \%$ to $28 \%$ due to low rate of air swirl and improper mixing of air and fuel. If the swirl is weak the products of combustion are not swept away fast from the surface of the burning drop plate. This will further suffocate burning of fuel droplet. Hence to optimize swirl, inlet manifold as well as inlet valve with different shapes on its periphery can be made first and simulated through computational fluid dynamic. The software used for this project is Ansys. Results are compared for maximum swirl and turbulent kinetic energy and finally a physical model is prepared through some suitable materials and through machining.

The Swirl term used is to signify the 'turbulence' in the air-fuel mixture admitted in the suction stroke. Swirl is actually a vortex or combination of several vortices created in the air-fuel mixture during inductions. In S.I engines "Swirl" or simply words" turbulence "is one of the prominent factors, that influence the flame speed or reaction rate. The flame speed is quite low in non-turbulent mixtures and increase with increase in turbulence. This is due to additional physical intermingling of burning and unburned particles at the flame front which expedites reaction by increasing the rate of contact. The turbulence in the coming mixture is generated during the admission of air fuel mixture through comparatively narrow sections of the intake pipe, valve opening during suction stroke. So therefore, turbulence increases the rate of heat flow to cylinder wall, it also speeds up the chemical reaction by intimate mixing of fuel and air so that spark advanced may be reduced. This helps in burning lean mixture also. The increase of flame speed due to turbulence reduces the combustion duration and hence minimizes the tendency of abnormal combustion. It may be noted that the excessive turbulence in air-fuel mixture may extinguished the flame resulting in rough and noisy operation of the engine.

The Swirling of the charge inside the combustion chamber is highly recommended for the complete combustion without leaving unburnt particles. It increases the flame propagation up to 10 times during the combustion and reducing the tendency of knocking and detonation. Flame propagation is increased by the induced turbulence and swirl induction which is just because of the engine design such as piston head profile, inclination and type of nozzle, operating 


\section{International Journal of Engineering Applied Sciences and Technology, 2019 \\ Vol. 4, Issue 4, ISSN No. 2455-2143, Pages 275-285 \\ Published Online August 2019 in IJEAST (http://www.ijeast.com)}

pressure etc. While a laminar flow of charge injected would reduce the flame propagation speed, causing the presence of unburnt particle inside the chamber and increasing the tendency to knock.

It has long been known that the introduction of swirl to a flow of reacting fluids can enhance the combustion process. Schwartz's experiment, demonstrated that rotating a propaneair mixture in an annular combustion chamber results in appreciable shortening of the flame length, Increased flame divergence, improved, stability characteristics and delayed blow off. Most flows that exist in nature or are utilized in applied sciences and engineering are turbulent. A turbulent flow is a time dependent chaotic three-dimensional flow which can be divided into a mean and fluctuating part. British fluid dynamist Osborne Reynolds (1842-1912) studied the transition conditions of laminar to turbulent flow in pipes, and the experiments he did led to formation of the famous dimensionless fluid mechanical Reynolds number.

\subsection{Problem Statement}

Due to heterogeneous combustion the thermal efficiency of C.I. Engine is less in spite of using a large excess air. Therefore, thought of conducting the experiment to overcome the problem of low thermal efficiency \& also to reduce levels of pollution. The thermal efficiency of the conventional C.I. Engine is low around $20 \%$ to $28 \%$ due to low rate of air swirl and improves the improper mixing of air and fuel. If the swirl is weak the products of combustion are not swept away fast from the surface of the burning drop plate. This will further suffocate burning of droplet. Hence to optimize swirl, inlet valve with different shapes on its periphery can be made first and simulated through computational fluid dynamic. But this system is not available in S.I engine (especially lower cc single cylinder engine). It would definitely increase efficiency and reduces the emissions, if we apply above system in S.I engine.

In some cases, above system is modified and swirling or turbulence is achieved near inlet valve in S.I engine i.e. BAJAJ DISCOVER DTS-SI (swirl induction). In S.I engine there is lack of proper mixing of air and fuel which causes us to think about implementing the swirling in inlet manifold. Nowadays we have fuel injectors instead of carburettor to have proper mixing of charge. Fuel injector already have the geometry for swirling of fuel, it will be beneficial if we swirl the air also in inlet manifold. So, the creation of turbulence or swirl of air as well as fuel will increase the thermal and volumetric efficiency, which increases proper combustion and eventually reduces the emissions.

Due to direct air coming through intake manifold without any geometry and directly strikes on the valve. Due to this also there is chances of change in valve timing. But this is very rare case. Hence swirling may help in various parameters as follows,

- $\quad$ Proper mixing of air fuel mixture.

- Increase thermal efficiency.
- Reductions in emissions.

- Increase in power output.

\subsection{Objective}

- Our first objective is to create swirl motion of air.

- Our second objective is to determine the velocity of air at swirl region and to calculate the distance covered by the swirl air, which can be calculated both on CFD as well as experimental setup.

- Our third objective is to compare the results obtained from CFD and experimentally.

- Our fourth objective is to implement this component in I.C engine which is our application as well as future scope.

\subsection{Scope}

The existing technology has swirling effect generated on the valve head of C.I engine. The same principle we are going to use in our project by designing geometries and then we are going to implement on S.I engine to check its performance parameters and its effect on output.

- The swirling phenomenon can be obtained by using different geometries and shapes.

- Comparison and validation result of swirling motion of fluid and non-swirled motion of fluid.

- Beside from that, this geometry can also be use in intercooler for proper heat transfer rate.

\subsection{Methodology}

The effective procedure of our project will be carried out in following ways:

- Selection of engine according to "CC":

- Nowadays, most of people are interested in engine having better fuel efficiency as well as economy (ranging from 125-150cc). Accordingly, we are going to select the $\mathrm{Cc}$ ranging from $125-150 \mathrm{Cc}$.

- Selection of existing or new geometry:

- we have three existing geometries to achieve swirling i.e.

- Rotational method.

- Tangential method.

- Passive method which consist of orifice, nozzlebased shape.

- By creating a new geometry, we can swirl the air.

- Using the optimum geometry, we made experimental setup through which we can calculate various velocities.

- To validate this velocity experimentally we put that velocity in CFD analysis and compare actual velocity to analytical velocity.

- After we conclude that our geometry is properly swirling geometry for engine. 


\section{International Journal of Engineering Applied Sciences and Technology, 2019 Vol. 4, Issue 4, ISSN No. 2455-2143, Pages 275-285 \\ Published Online August 2019 in IJEAST (http://www.ijeast.com)}

\section{EXPERIMENTAL SETUP}

\section{A. 2.1 Intake Manifold Requirements}

As modern engines are expected to feature good response characteristic, maximum performance i.e. high engine torque, and low fuel consumption while keeping pollutant emissions at minimum, intake manifold should have to meet following requirements.

- Fast mixture delivery.

- Low pressure loss.

- Uniform mixture distribution.

- Low fuel-film accumulation.

Moreover, the intake manifold in its capacity as a connecting element between the mixture formation system and cylinder head is subject to substantial mechanical, thermal and chemical wear.

Below follows a description of most important factor influencing volumetric efficiency, mixture distribution and wall film formation in induction system with single point mixture formation. It not only describes relationship, but also gives practical hint as how to improve intake manifold dimensioning.

\section{B. 2.2 Design Principle}

Some design principle applies to all intake manifolds with single-point formation independent of a particular induction system, or engine design, or of the chosen intake manifold type. These general guidelines can be grouped under three requirements that have to be met by the intake manifold geometry:

- Spatial symmetry

- Temperature symmetry

- Time symmetry.

The first requirement seems to be perfectly logical fundamental precondition for the uniform distribution of the air/fuel mixture from the mixture formation system to be individual cylinders.

Intake manifold design must be symmetrical in relation to a plane through the mixture formation system center and vertical to the engine axis. The mixture formation system is always is deployed in the middle between the outer and inner inlet duct pairs as most all the disturbance is caused in the mixture formation system are very sensitive matter, asymmetrical intake manifold design cannot be recommended as a solution to equalize as a symmetrical flow that may have developed in mixture formation system.

while such flow distribution might be successful compensated in one mixture formation system they could easily amplified when using another mixture formation system, often simply because of manufacturing tolerances.

The demand for temperature symmetry seems just as logical as the one for spatial/dimensioning symmetry. While the latter eliminates the danger of asymmetrical design of manifold heating system, an asymmetrical temperature distribution inside intake manifold can well be feasible by intake manifold positioning in the engine compartment.

Depending on motoring conditions, the individual runner facing longitudinally deployed engine are exposed to considerably higher variation in the temperature which leads to differing fuel vaporization in the front and near intake manifold valves.

\section{2.3 Turbulence/Swirling}

The carburetor or the fuel injectors spray fuel droplets into the air at end the intake manifold. Due to electrostatic forces some of the fuel will form into pools along the walls of the manifold, or may converge into larger droplets in the air.

Both actions are undesirable because they create inconsistencies in the air-fuel ratio. Turbulence in the intake causes forces of uneven proportions in varying vectors to be applied to the fuel, aiding in atomization.

Better atomization allows for a more complete burn of all the fuel and helps reduce engine knocking by enlarging the flame front.

To achieve this turbulence, it is a common practice to leave the surfaces of the intake and intake ports in the cylinder head rough and unpolished.

Only a certain degree of turbulence is useful in the intake. Once the fuel is sufficiently atomized additional turbulence causes unneeded pressure drops and a drop-in engine performance.

\section{2.4 Selection of Material}

Intake manifold of the Internal Combustion engine is a subsystem which supplies fresh air-fuel mixture into the engine cylinders where combustion of fuel takes place. For Efficient Combustion of the charge, the walls of the intake manifold must be smooth/polished to reduce any sidewall resistance.

The traditional materials used for intake manifolds were cast iron and Aluminum. In order to reduce manufacturing costs and improve thermal efficiency, new composites are proposed. Inside the cylinder, the energy generated from combustion of fuel is converted into pressure and heat during the power stroke. The pressure and heat increase rapidly within a short span of time.

The piston converts this energy into mechanical work. In place of the traditional aluminum alloys, Al-SiC material is proposed which have superior properties. Exhaust manifold is responsible to remove the depleted charge and create space for the incoming charge.

Materials used in exhaust systems of engines must have High Temperature Service capability, superior fatigue strength, and good fracture toughness, be easily machinable and economic considering the overall cost of the automobile. Mo-Nb added ferritic stainless steel is a new material that is gaining reputation for its high formability and high heat-resistance. 


\section{International Journal of Engineering Applied Sciences and Technology, 2019 \\ Vol. 4, Issue 4, ISSN No. 2455-2143, Pages 275-285 \\ Published Online August 2019 in IJEAST (http://www.ijeast.com)}

The intake manifold has historically been manufactured from aluminum or cast iron, but use of composite plastic materials is gaining popularity.

Chrysler 4-cylinders, Ford Zetec 2.0, Duratek 2.0 and 2.3, and GM's Ecotec series are most popular composite plastic material used for designing inlet manifold.

Considering the expenditure, we are going to select aluminum for designing of inlet manifold.

But before that for experimental procedure, we are going to use the transparent acrylic material, through which the color die pattern will be visible properly.

\section{E. 2.5 Design of Inlet Manifold}

For the experimental procedure we have to take exact conditions which is happening in actual engine so Considering the specific single cylinder 150cc (i.e. Bajaj Pulsar 150) having some pressure at inlet and also the temperature and the mass flow rate.

We searched the inlet parameters and accordingly the various parameters are listed as follows,

- Displacement:149cc

- Max RPM:9000

- No. of cylinder:1

Theoretically, we can calculate the mass flow rate of the air that is coming as follows:

- $\mathrm{Ma}=\mathrm{Rpm} *($ Displacement/4)

- $\mathrm{Ma}=9000 *(0.000149 / 4)$

- $\mathrm{Ma}=0.335 \mathrm{~m} 3 / \mathrm{min}$

Now, we have got the mass flow rate which is equal to $0.335 \mathrm{~m} 3 / \mathrm{min}$. So according to reference book H.P. Lenz Mixture formation of S.I engine, the diameter which is equivalent to the above mass flow rate of air is $35 \mathrm{~mm}$.

So, according to the standard dimension of acrylic pipe we have i.e. $32 \mathrm{~mm}$ the dimension of the inlet manifold component must be equivalent to $32 \mathrm{~mm}$ to get desired result. The new dimension of component is $32 \mathrm{~mm}$.
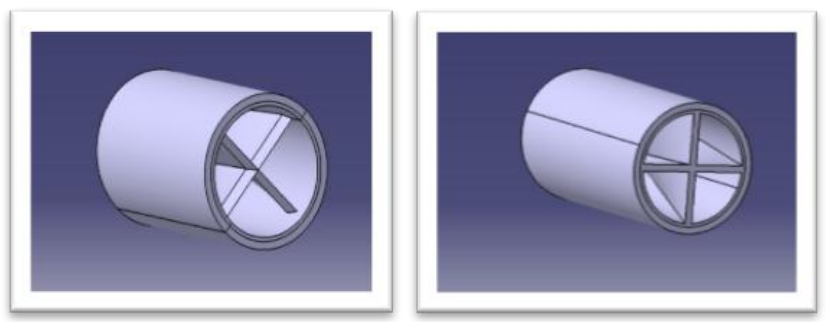

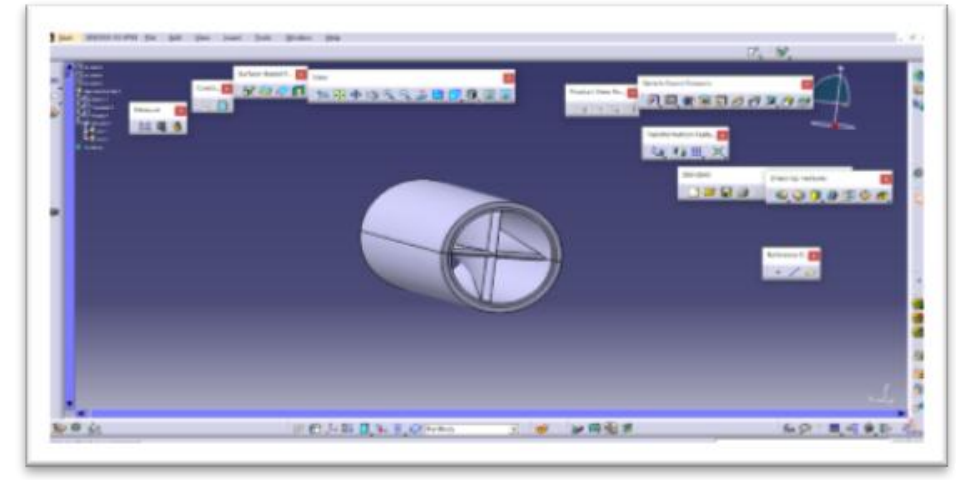

Fig no. 2.5.1.

\section{F. 2.6 Design of Inlet Manifold Runner}

The main objective of inlet manifold is to supply adequate amount of air with minimum pressure losses in case of S.I engine so whatever the conditions are there for engine we have to take it.

From reference book (i.e. H.P. Lenz Mixture formation in S.I engine), to have minimum pressure losses the cross-section area of manifold must be circular and should have minimum c/s or with no bents and also with complex geometry.

To have maximum volumetric efficiency the runner length must be as small as possible.

From reference book (i.e. Fuel Injection and control for I.C engine by Paul G Burman), the length of the runner for maximum efficiency must be between 4 to 7 inches i.e. 7 to 10 $\mathrm{cm}$.

So, for our experimentation the length of the runner is $10 \mathrm{~cm}$.

\section{G. 2.7 Components}

As our main objective is to make a swirl pattern of the fluid that is passing through the manifold. In our CFD analysis we have seen the swirl pattern of the fluid and got the results, to justify the result we have to make a model or directly install the component in the inlet manifold. So, we approached ARAI (Automotive Research association of India) near Kothrud. We approached there and got to know that the costing goes around thirty-five to forty thousand which is not at all affordable for any of us.

We and our guide decided to make a model and identify the swirl pattern by passing the fluid through the pipe and seeing the pattern physically and comparing it with the one without component. The various components which we needed for our experimental setup are as follows:

- Swirling component

- Acrylic pipe

- Water Pump

- Color die

- Tank storage

- Flow regulator

The swirling component is the most important part as it creates the turbulence which we have to observe. To observe 


\section{International Journal of Engineering Applied Sciences and Technology, 2019 \\ Vol. 4, Issue 4, ISSN No. 2455-2143, Pages 275-285 \\ Published Online August 2019 in IJEAST (http://www.ijeast.com)}

the flow pattern a transparent pipe is required. We have taken acrylic pipe for this purpose. The water pump is required which pump the water. The working fluid use is water. Color die is dropped inside the transparent pipe containing the fluid which will help to identify the pattern made by water.

The various devices use for measuring various parameters are as follows;

Swirling component: A separate component is design to achieve the swirling or turbulence pattern inside the inlet manifold to get the desired result. The component has the dimension of diameter 32 having length of $160 \mathrm{~mm}$. The component has 4 blades which have been design to obtain the turbulence pattern of the fluid that will pass through it.

Color die: In experimental setup first of all we observe the pattern of fluid without using the color die. Then we add the color die with that fluid which is coming from blower and then at last after passing that fluid from swirling device we are going to observe the color die pattern again. From that we get to know about swirling effect.

Acrylic Pipe: Acrylic pipe is a transparent pipe used to observe the pattern of the fluid that is flowing through it. Its internal diameter is $32 \mathrm{~mm}$ and it is kept transparent to observe the pattern of the flow. The pipe must be of larger length to get steady flow of water free from bubbles to get clear vision of pattern.

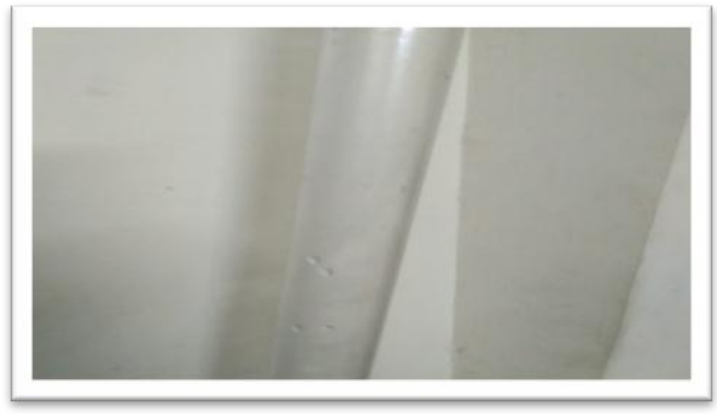

Fig No.2.7.1

Pump: To generate water flow inside the manifold. Pump is defined as machine which is used to produce large discharge of water with moderate increase in pressure. It consists of wheel with simple small blades on its circumference, and a casing to direct the flow of water out toward the edge. The casing on the centre of the wheel uses centrifugal forces to propel the air forward into the open.

\section{Specification:}

- Name: SELFPRIMING MONOBLOCK PUMP (ORIENT)

- Model: VRSP-60

- KW/HP: $0.37 / 0.5$

Phase: Single
- $\quad$ Pipe Size: $25 * 25 \mathrm{~mm}$

- Speed: $2760 \mathrm{rpm}$

- Body: Aluminum

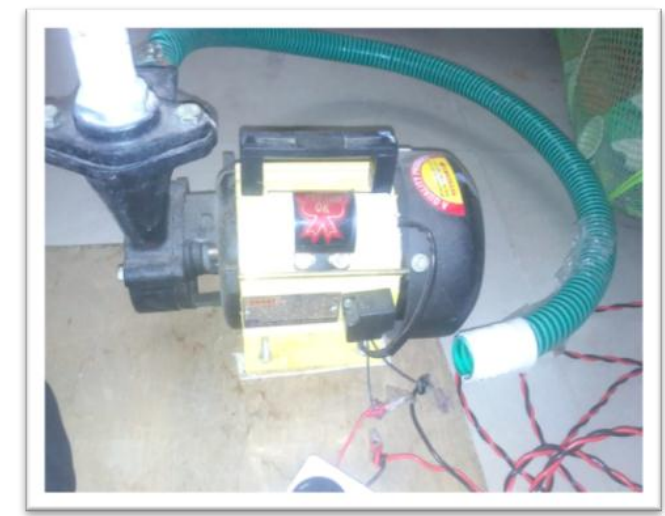

Fig No.2.7.2

Flow regulator: To control the flow of water from the pump. Function of a flow control regulation is self -evident from its name. A flow control regulates the rate of water which is flowing through acrylic pipe. The control of water can be done by adjusting the resistance of current to control the rpm of the motor which controls the discharge of the motor. It is a 2000watt regulator.

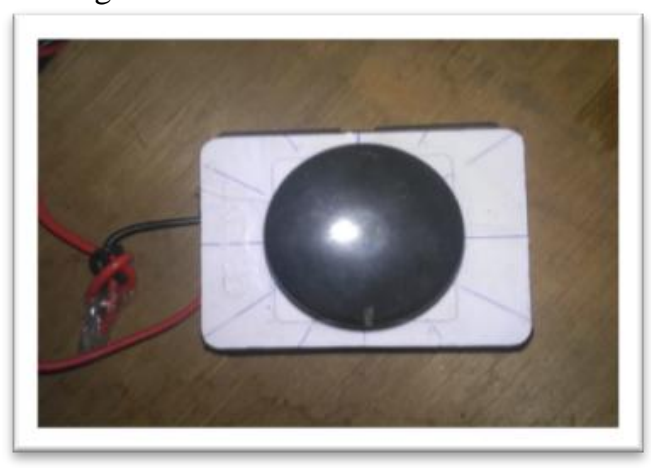

Fig No.2.7.3.

Storage Tanks: Two storage tank are used. One at the inlet of the pump and other one at its outlet. The main objective of the tank is to provide water at inlet of the pump and to calculate discharge of the pump. The dimension of the tank is $800 * 685 * 200 \mathrm{~mm}$ having thickness $0.5 \mathrm{~mm}$. 


\section{International Journal of Engineering Applied Sciences and Technology, 2019 \\ Vol. 4, Issue 4, ISSN No. 2455-2143, Pages 275-285 \\ Published Online August 2019 in IJEAST (http://www.ijeast.com)}
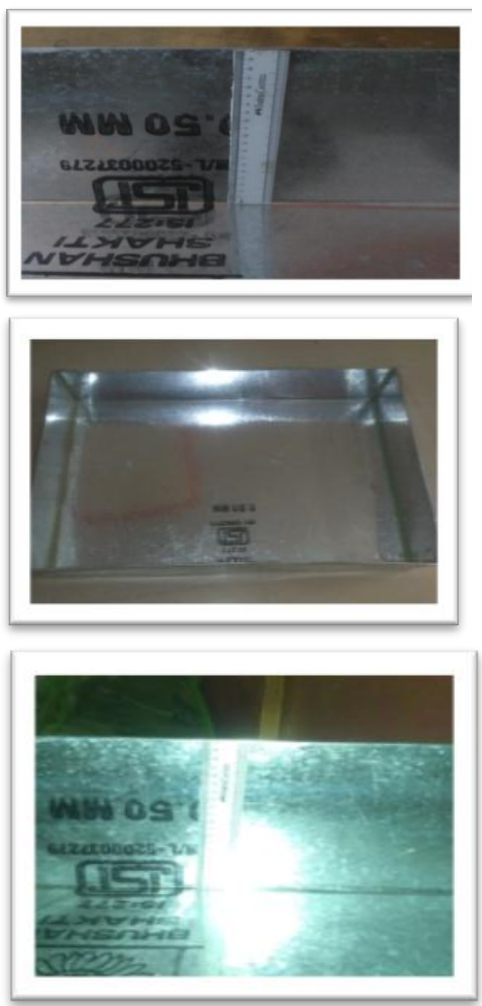

Fig No.2.7.4.

\section{G. 2.8 Experimental Procedure}

- When the pump is started, the water flow takes place inside the system which is the most important factor.

- Various fluids are going to be used to check the turbulence created inside the system, firstly the behavior of water is going to determined followed by combination of two fluids i.e. water and color die.

- The discharge of the system will be calculated by measuring volume of water per unit time (i.e. $30 \mathrm{sec}$ ) inside the system and then velocity can be determined.

- Likewise, we are going to take 5 readings with different position of regulator we are going to get different discharge which will eventually give different velocity.

- As the water is passed through the swirling geometry, we can identify the water pattern by allowing the color die.

- CFD analysis is done with ANSYS software by keeping the pressure and flow rate as parameter and results are obtained.

- By doing the analysis on software we can compare the result obtain from experimental setup and CFD result.

- Once the swirling or turbulence is achieved, then we are ready to go for actual engine setup followed by CFD analysis.

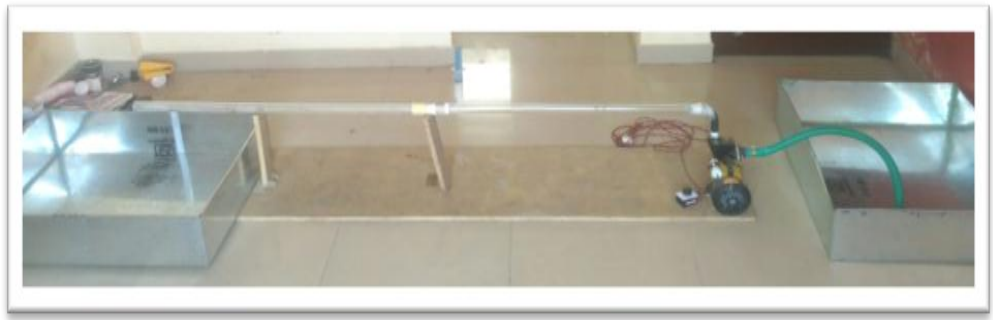

Fig No. 2.8.1.

\section{ANALYTICAL PROCEDURE}

For design purpose we have used CATIA software as it is user friendly for part as well as surface design. As our inner diameter is fix to $32 \mathrm{~mm}$ we have design three different geometries as follows,

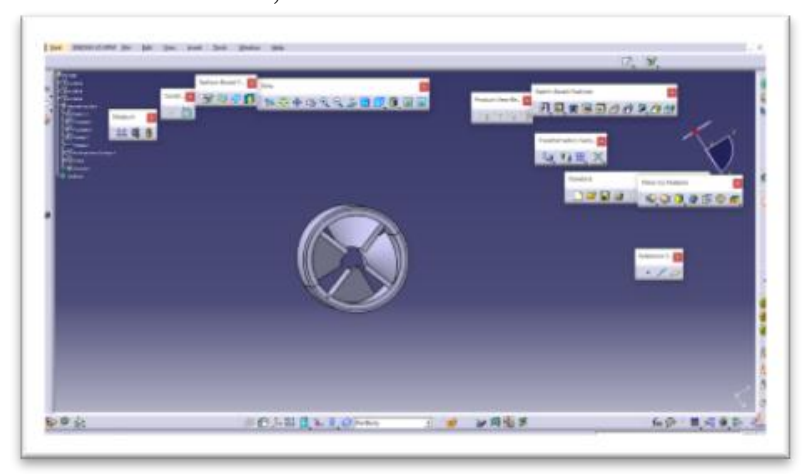

Fig no. 3.1. geometry 1

In our application of inlet manifold, air is passed axially and our objective is to obtained swirl motion instead of axial motion. To obtain the swirl motion we have designed the component having twisted blade geometry. In this geometry, the angle between inlet blade tip to outlet blade tip is 40 degree having interval of 20 degree in two steps having a length of $30 \mathrm{~mm}$. Here the center portion is kept hollow because the more focus is given on air near the wall.

In second geometry, we have given the angle between inlet blade tip to outlet blade tip is 70 degree having interval of 35 degree at two steps having length of $30 \mathrm{~mm}$ and rest design is the same.

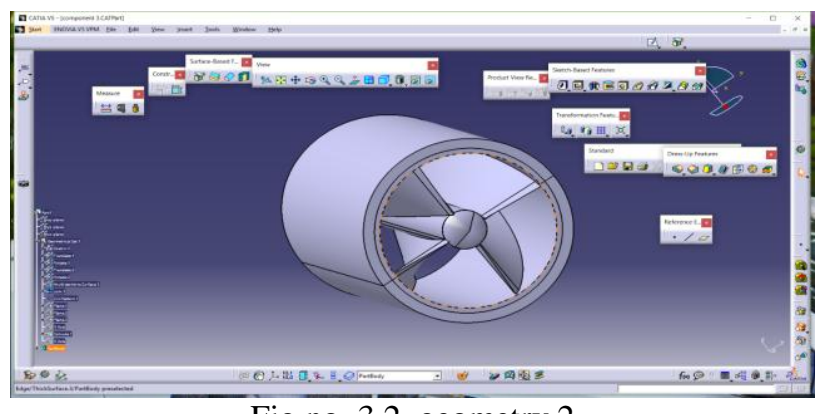

Fig no. 3.2. geometry 2 


\section{International Journal of Engineering Applied Sciences and Technology, 2019 \\ Vol. 4, Issue 4, ISSN No. 2455-2143, Pages 275-285 \\ Published Online August 2019 in IJEAST (http://www.ijeast.com)}

In this geometry, keeping the blade angle as 70 degree, we have covered the middle section to utilize the air which is going without swirl in geometry 1 . The center part is given a conical shape as aerodynamical shape to maintain the least resistance to air.

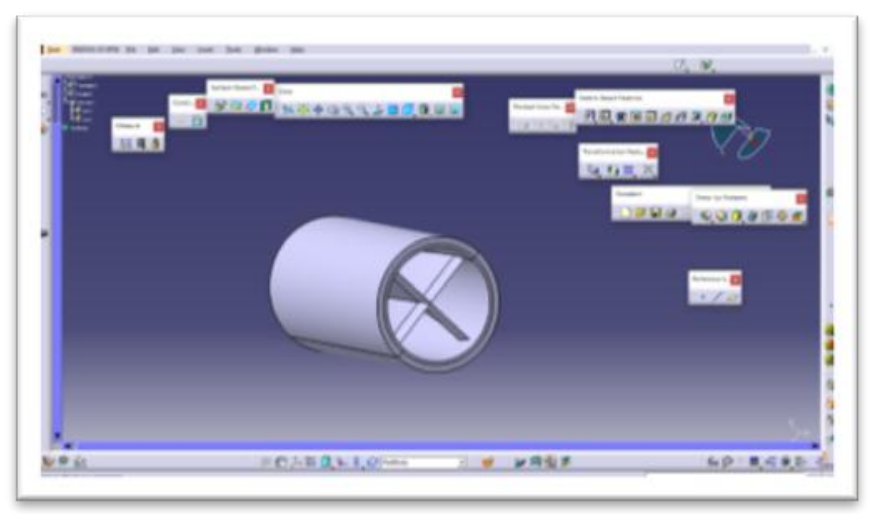

Fig no. 3.3. geometry 3

We have observed in previous geometry that, its result in eddies formation which results in less velocity compare to geometry 1 . To overcome this problem, we have designed the geometry keeping blade angle same as 70 degree but the difference is that the blades are merged to each other in perpendicular have aerodynamic shape.

Based on these three geometries we have done CFD analysis and we got the result as follows,

\section{For Geometry 1:}

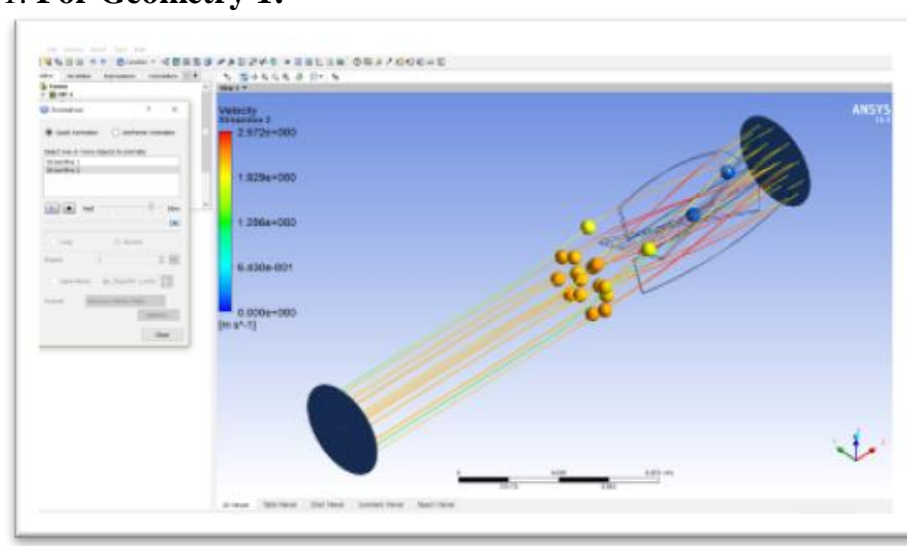

Fig no. 3.4.

As we can see from above figure, when we give velocity 2 $\mathrm{m} / \mathrm{s}$, the velocity inside the component is around $2.57 \mathrm{~m} / \mathrm{s}$ approximate and the velocity at outlet of the component with certain distance is $2.2 \mathrm{~m} / \mathrm{s}$ to $2.3 \mathrm{~m} / \mathrm{s}$. At certain distance the flow changes to laminar.

\section{For Geometry 2:}

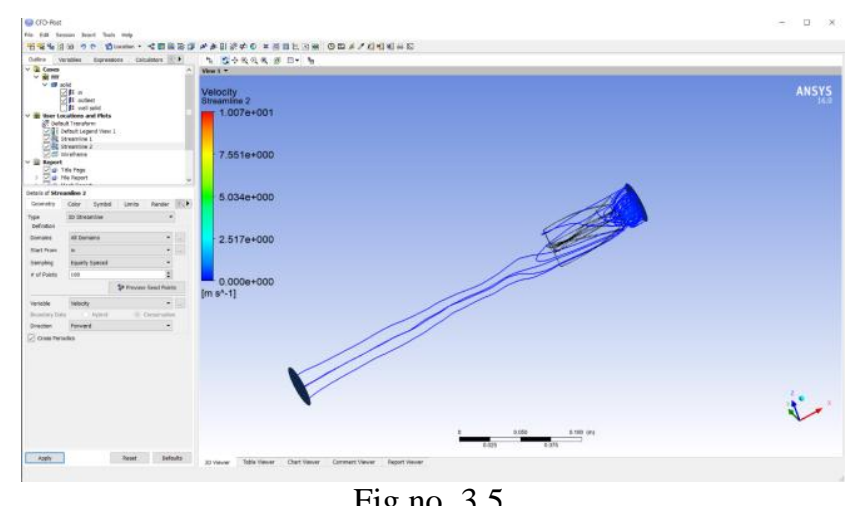

Fig no. 3.5.

As we can see from above figure of geometry 2, due to the addition of the conical part at the center, it exerts the backflow which reduces the velocity drastically.

\section{For Geometry 3:}

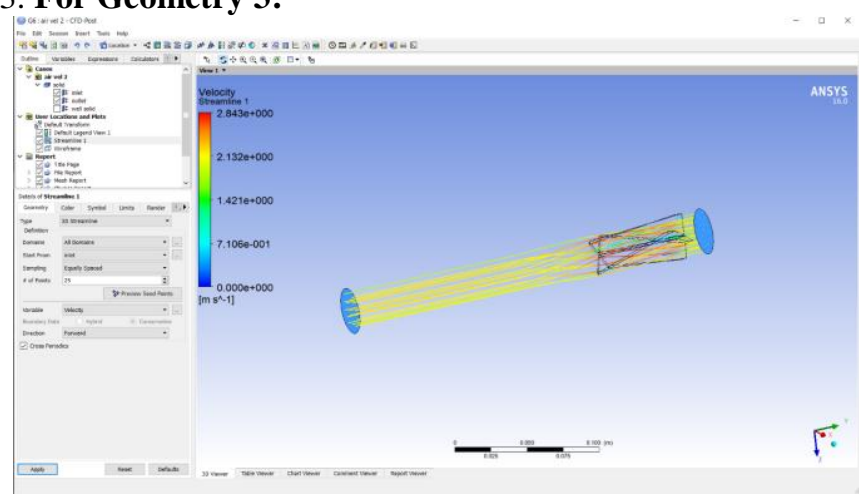

Fig no. 3.6.

In this geometry, we can see that there is less resistance to flow due to elimination of the conical part. Along with the aerodynamic shape of blade, it offers little resistance to the flow. The velocity of flow in the component is around $2.8 \mathrm{~m} / \mathrm{s}$ whereas at outlet of component the velocity changes to $2.3 \mathrm{~m} / \mathrm{s}$ $2.2 \mathrm{~m} / \mathrm{s}$.

As we seen from these geometries, the swirl and its distance and velocity are much better in geometry to 1 and 3 . Since, the geometry 3 is aerodynamic as compared to the geometry 1 and from the result we have seen the swirl pattern and its distance is more than the previous one. In geometry 3 we are getting max velocity of $2.8 \mathrm{~m} / \mathrm{s}$ compared to $2.57 \mathrm{~m} / \mathrm{s}$ of geometry. So, we have taken geometry 3 as optimum geometry for further calculation.

Trial on optimum geometry:

1. Fluid (Air), Velocity $(2 \mathrm{~m} / \mathrm{s})$ : 


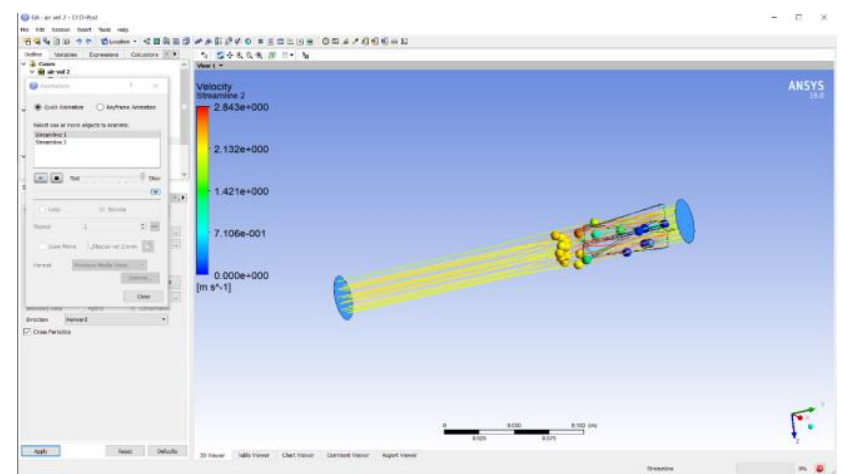

Fig no. 3.7.

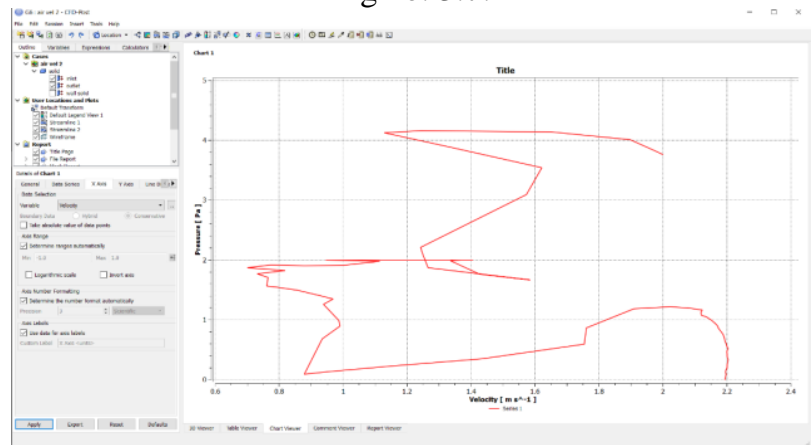

Fig no. 3.8.

Now, from the above figures 3.6 and 3.7, we can see that the result obtained from both the water as well as air are same but in case of air it is difficult to observe the flow pattern and to calculate the velocities. And hence as we are going to perform our experiment on water as it is most suitable for calculation. We have performed CFD using water for different velocities which we have calculated through experimentation and the results for those velocities are follows,

\section{Fluid (water), Velocity $(0.299 \mathrm{~m} / \mathrm{s})$ :}

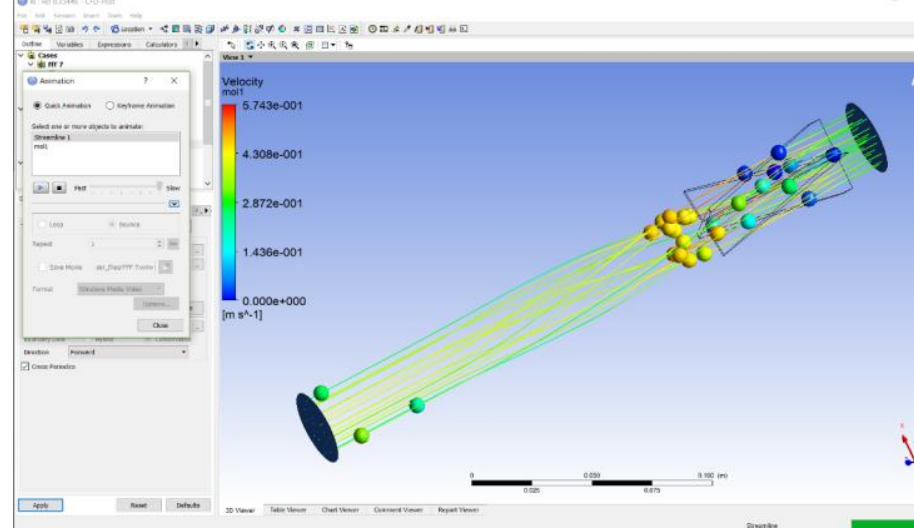

Fig no. 3.9.

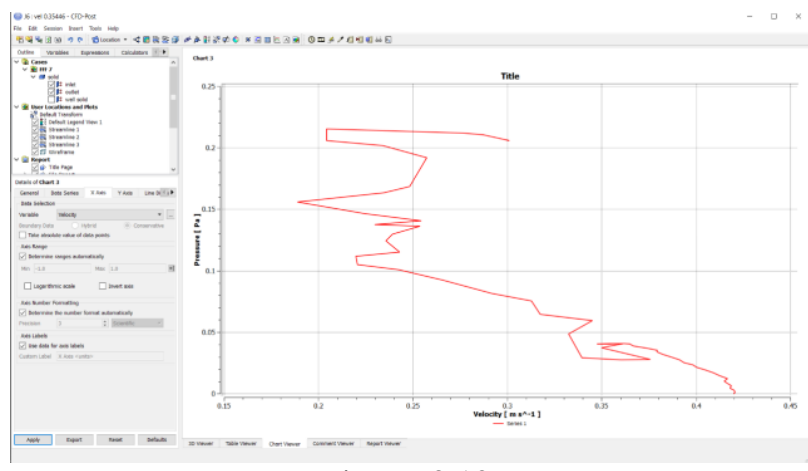

Fig no. 3.10.

When we give $0.299 \mathrm{~m} / \mathrm{s}$ as input we get output velocity as $0.354 \mathrm{~m} / \mathrm{s}$. The velocity in the component reaches to 0.5743 $\mathrm{m} / \mathrm{s}$ and as it goes further velocity reduces $0.42 \mathrm{~m} / \mathrm{s}$. The swirl motion travels approximately $0.15 \mathrm{~m}$ from the inlet.

\section{Fluid (water), velocity $(0.724 \mathrm{~m} / \mathrm{s})$ :}

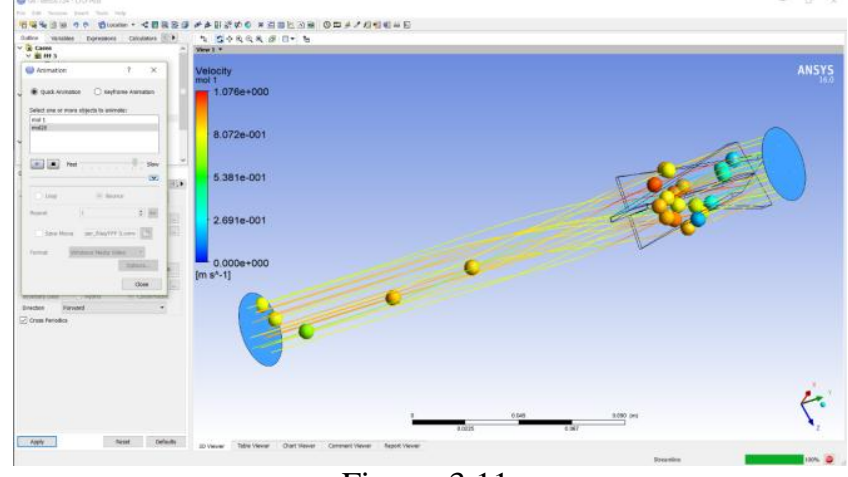

Fig no. 3.11.

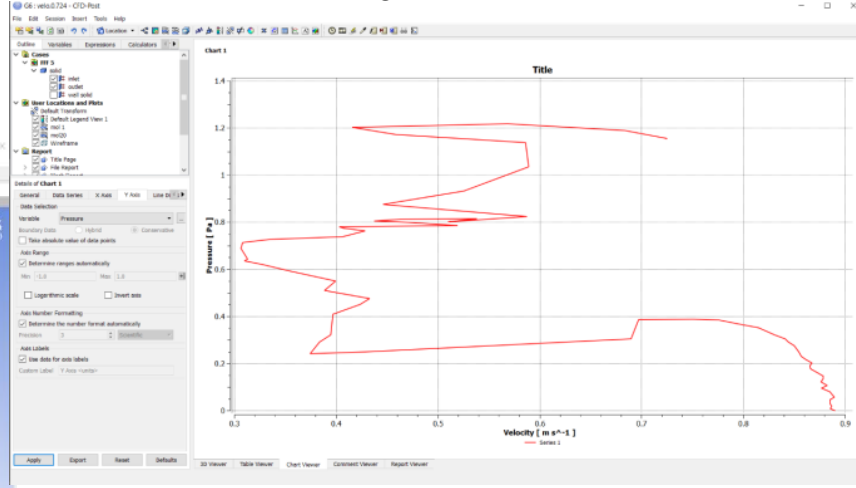

Fig no. 3.12.

When we give $0.724 \mathrm{~m} / \mathrm{s}$ as input velocity we get $0.8566 \mathrm{~m} / \mathrm{s}$ L. as output velocity. The velocity in the component reaches to $1.07 \mathrm{~m} / \mathrm{s}$ and as it goes further velocity reduces $0.899 \mathrm{~m} / \mathrm{s}$. The swirl motion travels approximately 0.13 from the inlet. 


\section{International Journal of Engineering Applied Sciences and Technology, 2019 \\ Vol. 4, Issue 4, ISSN No. 2455-2143, Pages 275-285 \\ Published Online August 2019 in IJEAST (http://www.ijeast.com)}

\section{Fluid (Water), Velocity $(0.799 \mathrm{~m} / \mathrm{s})$}

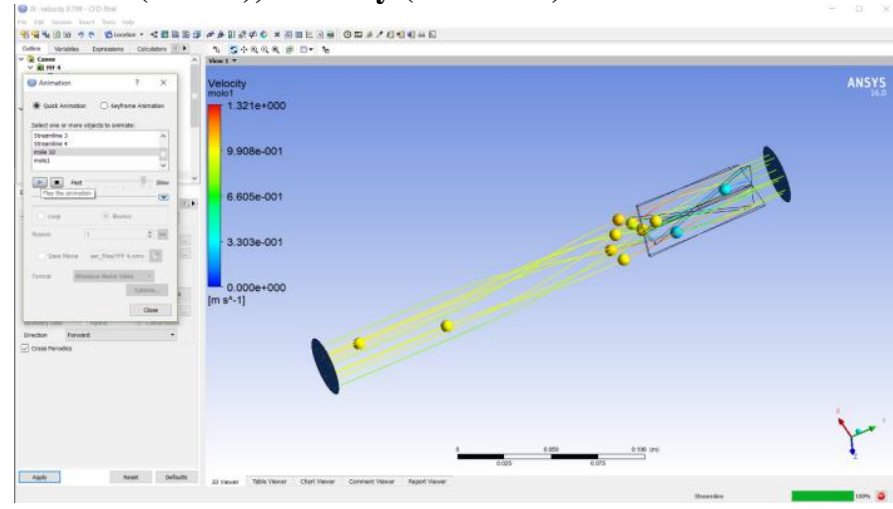

Fig no. 3.13.

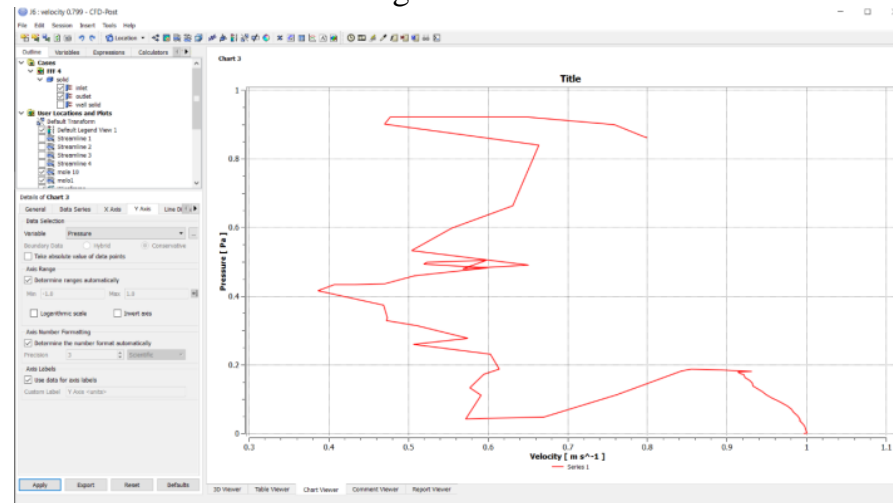

Fig no. 3.14.

When we use $0.799 \mathrm{~m} / \mathrm{s}$ as input velocity we get $0.9477 \mathrm{~m} / \mathrm{s}$ as output velocity. The velocity in the component reaches to 1.3 $\mathrm{m} / \mathrm{s}$ and as it goes further velocity reduces $1.023 \mathrm{~m} / \mathrm{s}$. The swirl motion travels approximately $0.15 \mathrm{~m}$ from the inlet.

\section{Fluid (water), Velocity $(0.499 \mathrm{~m} / \mathrm{s})$ :}

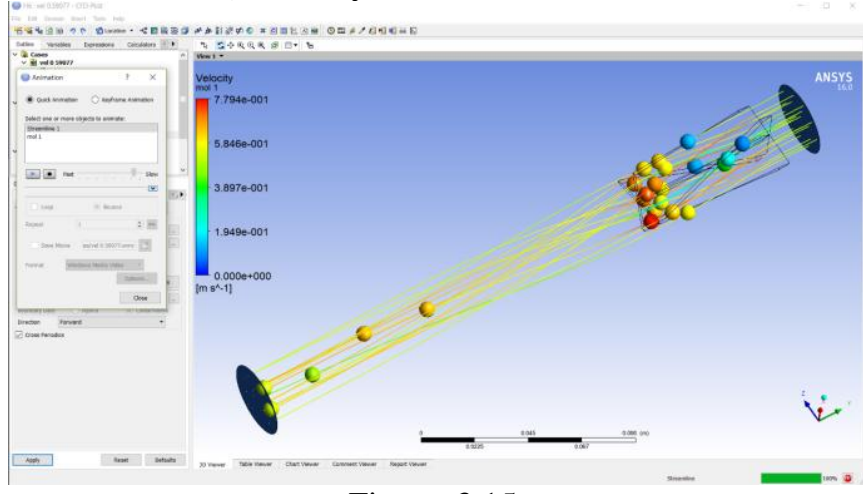

Fig no. 3.15.

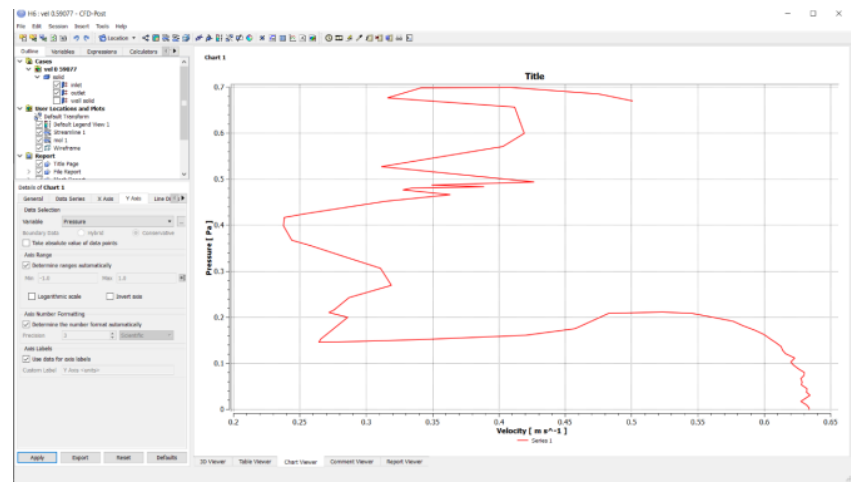

Fig no. 3.16.

When we use input velocity as $0.499 \mathrm{~m} / \mathrm{s}$ we get $0.590 \mathrm{~m} / \mathrm{s}$ as output velocity. The velocity in the component reaches to

$0.779 \mathrm{~m} / \mathrm{s}$ and as it goes further velocity reduces $0.6 \mathrm{~m} / \mathrm{s}$. The swirl motion travels approximately 0.14 from the inlet.

\section{CALCULATION AND RESULT}

Dimensions of tank: - length: $880 \mathrm{~mm}$ Width: $685 \mathrm{~mm}$

Pipe internal diameter: - $32 \mathrm{~mm}$

Area of pipe: -

$\mathrm{A}=\pi \mathrm{d}^{\wedge} 2 / 4=\pi^{*} 32 \wedge 2 / 4=804.247 \mathrm{~mm}^{\wedge} 2=804.247^{*} 10^{\wedge}(-6)$ $\mathrm{m}^{\wedge} 2$

Area of geometry: -

$\mathrm{A}=804.247-(2 * 2+4 * 2 * 15)=680.24 \mathrm{~mm}^{\wedge} 2=680.24 * 10^{\wedge}$ $(-6) \mathrm{m}^{\wedge} 2$

Observations table: -

\begin{tabular}{|c|c|c|c|c|c|}
\hline \multirow{2}{*}{$\begin{array}{c}\text { Sr } \\
\text { No. }\end{array}$} & $\begin{array}{c}\text { Regulator } \\
\text { line }\end{array}$ & \multirow{2}{*}{$\begin{array}{c}\text { Time, } \mathrm{t} \\
(\mathrm{sec})\end{array}$} & \multicolumn{2}{|c|}{$\begin{array}{c}\text { Height reading } \\
(\mathrm{cm})\end{array}$} & \multirow{2}{*}{$\begin{array}{c}\text { Difference } \\
(\mathrm{cm})\end{array}$} \\
\cline { 4 - 6 } & & & $\begin{array}{c}\text { After } \\
\text { reading }\end{array}$ & $30 \mathrm{sec}$ & \\
\hline 1 & 2 & 30 & 8.5 & 11.7 & 3.2 \\
\hline 2 & 3 & 30 & 5.1 & 8.3 & 3.2 \\
\hline 3 & 4 & 30 & 5.5 & 8.4 & 2.9 \\
\hline 4 & 5 & 30 & 2 & 4 & 2 \\
\hline 5 & 6 & 30 & 8.5 & 9.7 & 1.2 \\
\hline
\end{tabular}

Table.no. 4.1

\section{Result}

\begin{tabular}{|c|c|c|c|c|}
\hline $\begin{array}{c}\text { Sr } \\
\text { No. }\end{array}$ & $\begin{array}{c}\text { Difference } \\
(\mathrm{m})\end{array}$ & $\mathrm{L}^{*} \mathrm{~B}\left(\mathrm{~m}^{\wedge} 2\right)$ & $\begin{array}{c}\mathrm{L} * \mathrm{~B} * \mathrm{H} \\
\left(\mathrm{m}^{\wedge} 3\right)\end{array}$ & $\begin{array}{c}\text { Discharge, } \\
\mathrm{Q}=\mathrm{L}^{*} \mathrm{~B} * \mathrm{H} / \mathrm{t} \\
\left(\mathrm{m}^{\wedge} 3 / \mathrm{s}\right)\end{array}$ \\
\hline 1 & $\begin{array}{c}32 * 10^{\wedge}(- \\
3)\end{array}$ & $0.88 * 0.685$ & 0.01928 & $\begin{array}{c}6.4266^{*} 10^{\wedge} \\
(-4)\end{array}$ \\
\hline 2 & $\begin{array}{c}32 * 10^{\wedge}(- \\
3)\end{array}$ & $0.88 * 0.685$ & 0.01928 & $\begin{array}{c}6.4266^{*} 10^{\wedge} \\
(-4)\end{array}$ \\
\hline 3 & $\begin{array}{c}29 * 10^{\wedge}(- \\
3)\end{array}$ & $0.88 * 0.685$ & 0.0174812 & $\begin{array}{c}5.8270^{*} 10^{\wedge} \\
(-4)\end{array}$ \\
\hline 4 & $\begin{array}{c}20^{*} 10^{\wedge}(- \\
3)\end{array}$ & $0.88 * 0.685$ & 0.012056 & $\begin{array}{c}4.0186^{*} 10^{\wedge} \\
(-4)\end{array}$ \\
\hline
\end{tabular}


International Journal of Engineering Applied Sciences and Technology, 2019

Vol. 4, Issue 4, ISSN No. 2455-2143, Pages 275-285

Published Online August 2019 in IJEAST (http://www.ijeast.com)

\begin{tabular}{|c|c|c|c|c|}
\hline 5 & $\begin{array}{c}12 * 10^{\wedge}(- \\
3)\end{array}$ & $0.88 * 0.685$ & 0.0072336 & $\begin{array}{c}2.4112^{*} * 10^{\wedge} \\
(-4)\end{array}$ \\
\hline
\end{tabular}

Table.no. 4.2

To find velocity, $\mathrm{V}$

We know that, $\mathrm{Q}=\mathrm{A} * \mathrm{~V}$

Volume, $\mathrm{V}=\mathrm{L} * \mathrm{~B} * \mathrm{H}$.

\begin{tabular}{|c|c|c|c|c|c|c|}
\hline 4 & $\begin{array}{c}680.24 \\
* 10^{\wedge}(- \\
6)\end{array}$ & $\begin{array}{c}4.0186 \\
* 10^{\wedge}(- \\
4)\end{array}$ & $\begin{array}{c}4.0186^{*} 1 \\
0^{\wedge}(-4) / \\
680.24 * 1 \\
0^{\wedge}(-6)\end{array}$ & $\begin{array}{c}0.590 \\
77\end{array}$ & 0.634 & 6.81 \\
\hline 5 & $\begin{array}{c}680.24 \\
* 10^{\wedge}(- \\
6)\end{array}$ & $\begin{array}{c}2.4112 \\
* 10^{\wedge}(- \\
4)\end{array}$ & $\begin{array}{c}2.412^{*} 1 \\
0^{\wedge}(-4) / \\
680.24^{*} 1 \\
0^{\wedge}(-6)\end{array}$ & $\begin{array}{c}0.354 \\
46\end{array}$ & 0.423 & 6.85 \\
\hline
\end{tabular}

Table.no. 4.4

\section{CONCLUSION}

As per our application of IC engine, the resistance offered to air flow must be minimum as possible along with greater swirl motion and distance travelled. From designed geometries, the velocity obtained in geometry 3 is much larger when there is direct contact between the fluid and the geometric periphery because of less resistance as compared to other geometries. Having aerodynamically shape offered less resistance to flow which eventually maximizes the velocity. Here we conclude that geometry 3 is most useful geometry for our application. As we know the area of the pipe and discharge, we have calculated different velocities respective to different discharge shown in Table No.6.2.

Further, we calculated the area of geometry practically and calculated the velocities with respective to their discharge and calculated velocity obtained inside the geometry shown in Table No.6.3. Now, we took those respective velocity as inlet velocity and performed the CFD analysis and generated the results shown in table No.6.3. From the generated results we can see that the velocity in the geometry is approximately matches to the result calculated practically. Some error is obvious because CFD generates result with certain assumption and performing experiment practically has various losses are associated with it. To prove the values obtained from CFD and experimental setup are similar, the percent error between those values must fall below $10 \%$.

\section{REFERENCE}

\section{Journal Articles and Conference proceedings.}

1. Islek A. (2004). The impact of swirl in turbulent pipe flow, Georgia Institute of Technology.

2. Muntean S. (2005). A numerical investigation of the $3 \mathrm{~d}$ swirling flow in a pipe with constant diameter, Centre of Advanced Research in Engineering Sciences.

3. Silva A. (2011). Influence of Spread/splash Transition Criteria on the Spray Impingement Modelling, 24th European Conference on Liquid Atomization and Spray Systems, Estoril, Portugal. 


\section{International Journal of Engineering Applied Sciences and Technology, 2019 \\ Vol. 4, Issue 4, ISSN No. 2455-2143, Pages 275-285 \\ Published Online August 2019 in IJEAST (http://www.ijeast.com)}

4. Naga V. (2011). The effect of air swirl in a diesel engine, African Journal of Scientific Research Vol. 3, No. 1.

5. Kumar S. (2012). A Review on of the effect of in cylinder air swirl on diesel engine performance and emission, International Journal of Recent advances in Mechanical Engineering (IJMECH), November 2012, Vol.1, No.2.

6. Kalpak A. (2012). Experimental study of turbulent flows through pipe bends, Royal Institute of Technology KTH Mechanics SE-100 44 Stockholm, Sweden.

7. Saad I. (2013). Guide vane swirl and tumble device to improve in-cylinder air flow of CI engine using vegetable oil, ICME.

8. Dr. Yerrennagoudaru H and others, (2014). Effect of Inlet air swirl on four stroke single cylinder diesel engine performance, Volume 2.

9. Rangadu V. (2014). Experimental study of the effect of in cylinder air swirl on diesel engine performance, Department of Mechanical Engineering, Sri Sai College of Engineering \&Technology, Anantapur, A.P India.

10. Farsirotou E. (2014). Experimental investigation of fluid flow in horizontal pipes system of various cross-section geometries, Technological Educational Institute of Thessaly, Department of Civil Engineering T.E. Larissa, 41110 Larissa, Greece.

11. Matson J. (2014). A Swirling Pipe Flow Course Project, American Society for Engineering Education.

12. Hess D and others. (2014). Flying PIV measurements in a driven IC engine flow, Institute of Mechanics and Fluid Dynamics, TU Bergakademie Freiberg, Freiberg, Germany.

13. Ashok B and others. (2015). CFD Modelling of Advanced Swirl Technique at Inlet-Runner for Diesel Engine, Department of Thermal and Energy Engineering, School of Mechanical Engineering, VIT University, Vellore.

14. Fulli A. (2015). Performance Analysis of IC Engine Based on Swirl Induction by Using CFD, International Journal of Advanced Research in Science, Engineering and Technology.

15. Desai S. (2015). Generation of Air swirl through Inlet Poppet Valve modification and to enhance performance on diesel engine, Volume 12.

16. Shirvan S. (2015). Experimental study of complex pipe flows, Royal Institute of Technology, SE-100, Stockholm Sweden.

17. Md. S Hoque. (2016). Effect of swirl flow on Heat transfer characteristic in a circular pipe, Department of mechanical engineering, BUET, Dhaka, Bangladesh.
18. Singh A. (2016). A Study on Laminar Pipe flow \& losses, International Journal of Innovations in Engineering and Technology (IJIET).

19. Rahi K. (2016). Experimental and numerical analysis of flow through pipe for different geometry, International Conference on Mechanical, Industrial and Energy Engineering.

20. Gobinath R. (2017). Analysis of Effect of Inlet Swirl in Four Stroke Single Cylinder Diesel Engine with Different Inlet Valve Geometries Using CFD. Department of Automobile Engineering, Satyabhama University.

21. Kumar V. (2017). Effect of intake swirl on the performance of single cylinder direct injection diesel engine. Department of Thermal and Energy Engineering, School of Mechanical Engineering, VIT University, Vellore.

22. Kudale P. (2017). Modification of Setup for Major Losses in Pipes to Determine the Exact Value of Friction Factor, International Journal for Scientific Research \& Development Vol. 5, Issue 02.

23. Cahyono B. (2018). Analysis of influence of masks flow on intake valve of gas and oil fuel engine-based simulation, International Journal of Marine Engineering Innovation and Research, Vol. 2(3).

\section{ARAI (Automotive Research Association of India) Reference Books}

1. Basshuysen V. (2009). Gasoline Engine with direct injection, system, development. (BOSCH),1st edition.

2. Burman G and Deluca F. (1962). Fuel injection and control. American Bosch Armament Corporation 1962 (2nd edition).

3. Zhao F, David L and Lai H. Automotive gasoline direct injection engines.

4. Lenz H. Mixture formation in S.I engine. 